\begin{tabular}{|c|c|}
\hline Title & Photochemical Method of Device Fabrication Starting from Molecular Crystals \\
\hline Author(s) & Naito, Toshio; Sugawara, Hideyuki; Inabe, T amotsu; Miyamoto, T akeshi; Niimi, Hironobu; A sakura, Kiyotaka \\
\hline Citation & $\begin{array}{l}\text { Molecular Cry stal s and Liquid Crystal s, 455(1), 311-316 } \\
\text { https://doi.org/10.1080/15421400600699012 }\end{array}$ \\
\hline Issue Date & 2006-10 \\
\hline Doc URL & http:/hdl.handle.net/2115/30130 \\
\hline Rights & $\begin{array}{l}\text { This is an electronic version of an article published in Naito, T; Sugawara, H; Inabe, T; Miyamoto, T; Niimi, H; } \\
\text { A sakura, K, Photochemical method of device fabrication starting from molecular crystals, MOLECULAR CRY STA LS } \\
\text { A ND LIQUID CRY ST A LS, 455(1), Oct. 2006, pp. 311-316. MOLECULAR CRY STA LS A ND LIQUID CRY STA LS } \\
\text { is available online at: http://www.informaworld.com/ }\end{array}$ \\
\hline Tyре & article (author version) \\
\hline File Information & MCLC455.pdf \\
\hline
\end{tabular}

Instructions for use 


\title{
Photochemical Method of Device Fabrication Starting from Molecular Crystals
}

\author{
Toshio Naito* \\ Creative Research Initiative "Sousei” (CRIS), Hokkaido University, \\ Kita 21, Nishi 10, Kita-ku, Sapporo, Hokkaido 001-0021, Japan
}

Hideyuki Sugawara and Tamotsu Inabe

Division of Chemistry, Graduate School of Scinece, Hokkaido University, Kita 10, Nishi 8, Kita-ku, Sapporo, Hokkaido 060-0810, Japan

Takeshi Miyamoto, Hironobu Niimi and Kiyotaka Asakura Catalysis Reasearch Center (CRC), Hokkaido University, Kita 21, Nishi 10, Kita-ku, Sapporo, Hokkaido 001-0021, Japan

* Corresponding author. E-mail: tnaito@mail.cris.hokudai.ac.jp

The conductivity of a silver salt of $N, N$ '-dicyanoquinonediimine irreversibly varied in approximate proportion to an illumination of a wide range of wavelengths. Depending on the illumination conditions, four different states $(\beta, \gamma, \delta$, and $\varepsilon)$ were obtained with different structures. The 
$\beta$ structure is in particular important, where the formal charge of the $N, N$ '-dicyanoquinonediimine molecules continuously decreased to -0.4 -0.35 with retaining the crystal structure, when we kept the temperature < $155^{\circ} \mathrm{C}$ during the illumination. The non-illuminated area of the sample retained its original electrical property with a well-defined interface, which enabled a fabrication of a junction-structure in the single crystal.

Keywords: photo-induced phenomena; molecular semiconductor-metal junction; $N, N^{\prime}$-dicyanoquinonediimine; charge-transfer; doping

\section{INTRODUCTION}

Recently we reported on a new method of persistent electrical resistivity control of the molecular materials containing photosensitive chemical species [1]. At present, the chemistry of this method is considered to be approximately similar to the silver halides photography. A silver salt of an organic $\pi$-acceptor molecular radical anion, $\operatorname{Ag}(\mathrm{DM})_{2}$ (DM = 2,5-dimethyl- $N, N^{\prime}$-dicyanoquinonediimine; Fig. 1$)$, is utilized instead of silver bromide. In the crystal of $\operatorname{Ag}(\mathrm{DM})_{2}$, the planar radical-anion species of DM stack to form a columnar structure [2]. The unpaired electrons on the radical-anion species delocalize along these columns, resulting in metallic conduction. Similar to $\mathrm{AgBr}$, exposure to ultraviolet-visible (UV-Vis) light of $\mathrm{Ag}(\mathrm{DM})_{2}$ leads to a partial charge transfer from the $\pi$-acceptor molecules to the silver ions in the solid state. This charge transfer corresponds to decrease of the $\pi$-electrons in number on the DM radical-anion 
species. Because the electrical conductivity is solely dependent on the $\pi$-electrons on the DM radical-anion species in $\operatorname{Ag}(\mathrm{DM})_{2}$, such charge transfer results in the decrease of conductivity of this material. What is more, illumination on a limited part of the sample resulted in the change in conduction only at the illuminated part; the rest of the sample retained the original metallic conduction. Such a scenario is supported by X-ray photoelectron spectra $(\mathrm{XPS})(\mathrm{Ag}, \mathrm{N})$, and Raman spectra $(\mathrm{C}=\mathrm{C}$ and $\mathrm{C}=\mathrm{N}$ stretching modes) [1]. In combination with photolithography or light-focusing techniques, these findings might open a new way to control electrical properties of a particular part of a molecular solid, which would lead to fabrication of devices with junction-strutures. In fact, using this method we demonstrated that one could produce an energy barrier in a single crystal of $\operatorname{Ag}(\mathrm{DM})_{2}$, which indeed exhibited rectifying behavior; i.e., characteristic behavior to diodes [1]. In addition to the partial charge transfer semiconductor phase, we have found several phases created according to the illumination time and power. Therefore we must understand the properties and structures of these new phases and their formation mechanism in order to establish and develop this method to control electrical conductivities with as high spatial resolution as possible. In this brief communication we investigated the heat effects and wavelength dependence in addition to the characterization of several phases.

\section{EXPERIMENTAL}

We used two light sources depending on the experiment. One (light source A) was a UV-VIS FIBER LIGHT SOURCE L7893 equipped with a 5 W-tungsten halogen lamp $(400-1100 \mathrm{~nm})$ and a $30 \mathrm{~W}-\mathrm{D}_{2}$ lamp (200-400 nm), and with optical fiber of $800 \mu \mathrm{m}$ in core diameter (numerical aperture $=0.22$ ) (HAMAMATSU PHOTONICS K. K.). Both 
of the lamps could be turned on/off independently, but the power of light could not be varied. The end of the fiber was placed as close to the surface as possible $(<150 \mu \mathrm{m})$. The output of the incident beam at the end of the fiber is typically $0.1-0.2 \mu \mathrm{W} \mathrm{cm} \mathrm{cm}^{-2}$ $\mathrm{nm}^{-1}$ at $300-550 \mathrm{~nm}, 0.2-1 \mu \mathrm{W} \mathrm{cm} \mathrm{nm}^{-1}$ at $200-300$ and $550-1100 \mathrm{~nm}$. In a typical run we used both of the $5 \mathrm{~W}$-tungsten halogen and the $30 \mathrm{~W}-\mathrm{D}_{2}$ lamps, when the power was $\sim 3 \mathrm{~mW}$ at the end of the fiber. The typical value of the fluctuation of the output during continuous illumination is $0.004 \%$ and the drift $0.3 \% \mathrm{~h}^{-1}$. The other (light source B) was a $\mathrm{Hg} / \mathrm{Xe}$ lamp (200 W; HAMAMATSU PHOTONICS K. K.) with a multimode optical fiber (1m-length, $\phi=5 \mathrm{~mm}$, numerical aperture $=0.22$ ) (SUPERCURE-203S UV LIGHTSOURCE; SAN-EI ELECTRIC). This light source was also equipped with a removable filter and an aluminum mirror for cutting off the light with wavelengths shorter than $\sim 250 \mathrm{~nm}$ and longer than $\sim 800 \mathrm{~nm}$, respectively. This could minimize heat involved in the irradiation of the sample. The power of light of this light source could be varied continuously up to $\sim 300 \mathrm{~mW}$ at the end of the fiber. The maximum power depended on the wavelength. When UV light of 200-250 nm was required, the filter was removed. During the illumination with the light source $\mathrm{B}$, the sample was set in a copper or brass stage as a heat reservoir, and the temperature was continuously monitored. An anomalous deviation $(>0.1 \mathrm{~K})$ from the room temperature (RT) then was not observed.

\section{RESULTS AND DISCUSSION}

\section{Optically “Doped” States without Heating Effects}

We obtained four different kinds of resultant states depending on the illumination conditions as shown in Table 1. Including the pristine material, let us tentatively call 
these series of states $\alpha, \beta, \gamma, \delta$ and $\varepsilon$, respectively. All the states should involve charge transfer (redox) reaction between the Ag ions and the DM species based on their characterizations. As for the production of these states, no dependences on the wavelengths of illumination were observed. This is consistent with the results of an optical study, where no evident charge transfer bands between the Ag ions and the DM species were observed in temperature-dependent polarized reflectance spectra [3].

The $\beta$-state occurred after illumination of $\operatorname{Ag}(\mathrm{DM})_{2}$ in the pristine $(\alpha-)$ state below $155^{\circ} \mathrm{C}$. The $\beta$-state turned out to be produced through purely optical processes, i.e. photochemical reactions, and not accessible with any thermal treatment [4]. The $\beta$-state shared with the $\alpha$-state the appearances (SEM photographs), X-ray diffraction (XRD) pattern, elemental analyses (C, H, N(\%)) and IR spectra (Fig. 2), though it exhibited different electrical behavior, Raman shifts and XPS. The N1s XPS peak in the $\beta$-state had a small shoulder corresponding to the charge transfer. The amount of charge transfer evaluated from XPS was consistent with that of Raman shift. While $\operatorname{Ag}(\mathrm{DM})_{2}$ in the $\alpha$-state exhibited metallic electrical behavior down to $\sim 100 \mathrm{~K}$, that in the $\beta$-state exhibited semiconducting behavior. Generally, the longer the illumination lasted, the higher the resistivity became. Judging from the Raman shifts, the formal charge of the DM species appeared to approach $\sim-0.40--0.35$, where the illumination effects might saturate. After illumination ceased, the new semiconducting $\beta$-state lasted more than a half year, and it was never transformed into the $\alpha$-state again. There should be small but definite structural differences between the $\alpha$ - and the $\beta$-states, which may make this transformation irreversible. Further detailed study is now in progress. 


\section{Other Related States}

When the $\alpha$-state $\operatorname{Ag}(\mathrm{DM})_{2}$ was heated at $155^{\circ} \mathrm{C}$, it suddenly turned into a brown amorphous solid ( $\gamma$-state). This state was a diamagnetic insulator. A series of detailed chemical, thermal, structural and spectroscopic analyses of the amorphous process proved that this transformation was a structural transition rather than a decomposition. Through the amorphization, not only the original well-defined shape of the single crystals of the $\alpha$-state, but also the mass of the sample, chemical stoichiometry and the molecular structure of the DM species were retained. The amorphization occurred sharply at $155^{\circ} \mathrm{C}$ irrespective of the atmosphere (under air or under dry nitrogen). The amorphous solid contained silver metal particles and DM molecules (X-ray absorption fine structures), but was insoluble to organic solvents. Phase separation did not occur to form bulk silver and neutral DM powder by any procedure. Comparison of IR and high resolution solid state NMR spectra clearly indicated that the neutral DM species had a different structure from the isolated neutral DM crystals.

When the $\alpha$-state $\operatorname{Ag}(\mathrm{DM})_{2}$ was heated at $\sim 160^{\circ} \mathrm{C}$ or strongly illuminated, it turned into a black solid ( $\delta$-state) or white solid ( $\varepsilon-$ state). Both of them were nearly amorphous; the XRD powder patterns of them showed only broad and small peaks corresponding to the reflections of bulk silver. Although we could not find clear differences in production conditions of these two states yet. It was difficult to convert one of the two states to the other by any procedure. The $\delta$-state contained small particles of bulk silver with $9 \mathrm{~nm}$ in the average diameter, and was still rich in the DM species (IR and elemental analysis), which nearly corresponded to the original 
stoichiometry (2:1). The $\varepsilon$-state was an aggregation of almost pure bulk silver particles $(\sim 65 \mathrm{~nm} \phi)$ with a contamination of organic substances. The $\varepsilon$-state is considered to be produced by heating and decomposition of $\operatorname{Ag}(\mathrm{DM})_{2}$. Diffuse scattering spectra (Fig. 3) suggested that the $\delta$-state should be insulating, while the $\varepsilon$-state should be metallic.

Acknowledgement. We would like to thank Prof. Tooru Atake at Tokyo Institute of Technology for valuable discussion on the thermal analyses, and also thank Dr. Miho Sasaki at Rigaku Corporation for the XRD-DSC measurements.

\section{REFERENCES}

[1] Naito, T., Inabe, T., Niimi, H., Asakura, K., Adv. Mater., 16, 1786(2004).

[2] Kato, R., Kobayashi, H., Kobayashi, A., Mori, T., Inokuchi, H., Chem. Lett., 1579(1987); Hünig, S., J. Mater. Chem., 5, 1469(1995).

[3] Yakushi, K., et al., Mol. Cryst. Liq. Cryst., 181, 217(1990).

[4] Naito, T., et al., submitted. 
Table 1 Different states derived from the pristine $(\alpha-) \operatorname{Ag}(\mathrm{DM})_{2}$ by illumination or thermally treatments.

\begin{tabular}{|c|c|c|c|c|c|}
\hline states & colors & crystallinity & $\begin{array}{c}\text { chemical } \\
\text { formula }\end{array}$ & properties & $\begin{array}{c}\text { typical conditions of } \\
\text { sampling }\end{array}$ \\
\hline$\alpha-$ & $\begin{array}{c}\text { dark } \\
\text { blue }\end{array}$ & crystalline & $\mathrm{Ag}(\mathrm{DM})_{2}$ & metallic & - \\
\hline$\beta-$ & $\begin{array}{c}\text { dark } \\
\text { blue }\end{array}$ & crystalline & $\mathrm{Ag}(\mathrm{DM})_{2}$ & semiconducting & $\begin{array}{c}368-700 \mathrm{~nm} \\
200 \mathrm{~mW} \mathrm{~cm}{ }^{-2}, 30 \\
\mathrm{~min},<155^{\circ} \mathrm{C}\end{array}$ \\
\hline$\gamma-$ & brown & amorphous & $\mathrm{Ag}(\mathrm{DM})_{2}$ & insulating & $155^{\circ} \mathrm{C} \leq$ \\
\hline$\delta-$ & black & amorphous & $\begin{array}{c}{ }^{* 1} \\
\mathrm{Ag}(\mathrm{DM})_{\mathrm{n}} ; \mathrm{n} \\
\leq 2\end{array}$ & $-{ }^{* 4}$ & $155 \leq T\left({ }^{\circ} \mathrm{C}\right) \leq \sim 200$ \\
\hline$\varepsilon-$ & white & amorphous $^{* 2}$ & $\mathrm{Ag}^{* 3}$ & $-{ }^{* 4}$ & $\sim 200{ }^{\circ} \mathrm{C} \leq$ \\
\hline
\end{tabular}

${ }^{* 1}$ with small crystallites of bulk Ag dispersed homogeneously

$* 2$ aggregation of small $(<100 \mathrm{~nm})$ crystallites of bulk Ag

${ }^{*} 3$ trace amount of $\mathrm{C}(<3 \%), \mathrm{H}(<0.3 \%)$ and $\mathrm{N}(<1 \%)$ were detected as a contamination.

${ }^{*} 4$ conducting behavior is yet to be measured. 
Figure Captions

Fig. 1 Molecular structure of DM.

Fig. 2 IR spectra in KBr pellets of (a) isolated neutral DM species, (b) $\alpha-$, (c) $\beta-$, (d) $\gamma-$, and (e) $\delta-\operatorname{Ag}(\mathrm{DM})_{2}$, respectively.

Fig. 3 Diffuse scattering spectra of (a) isolated neutral DM species, (b) $\alpha-$, (c) $\gamma-$, (d) $\delta$-, and (e) $\varepsilon-\operatorname{Ag}(\mathrm{DM})_{2}$, respectively. The inset shows (d) and (e) spectra with $f(R)$ enlarged by 10 times. 
$N_{s}$

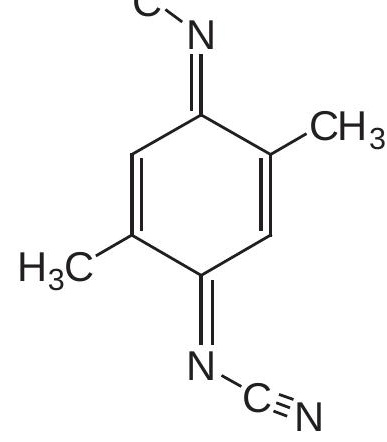

( Fig. 1 T. Naito et al.) 


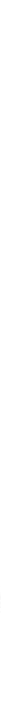

(Fig. 2 T. Naito et al. ) 


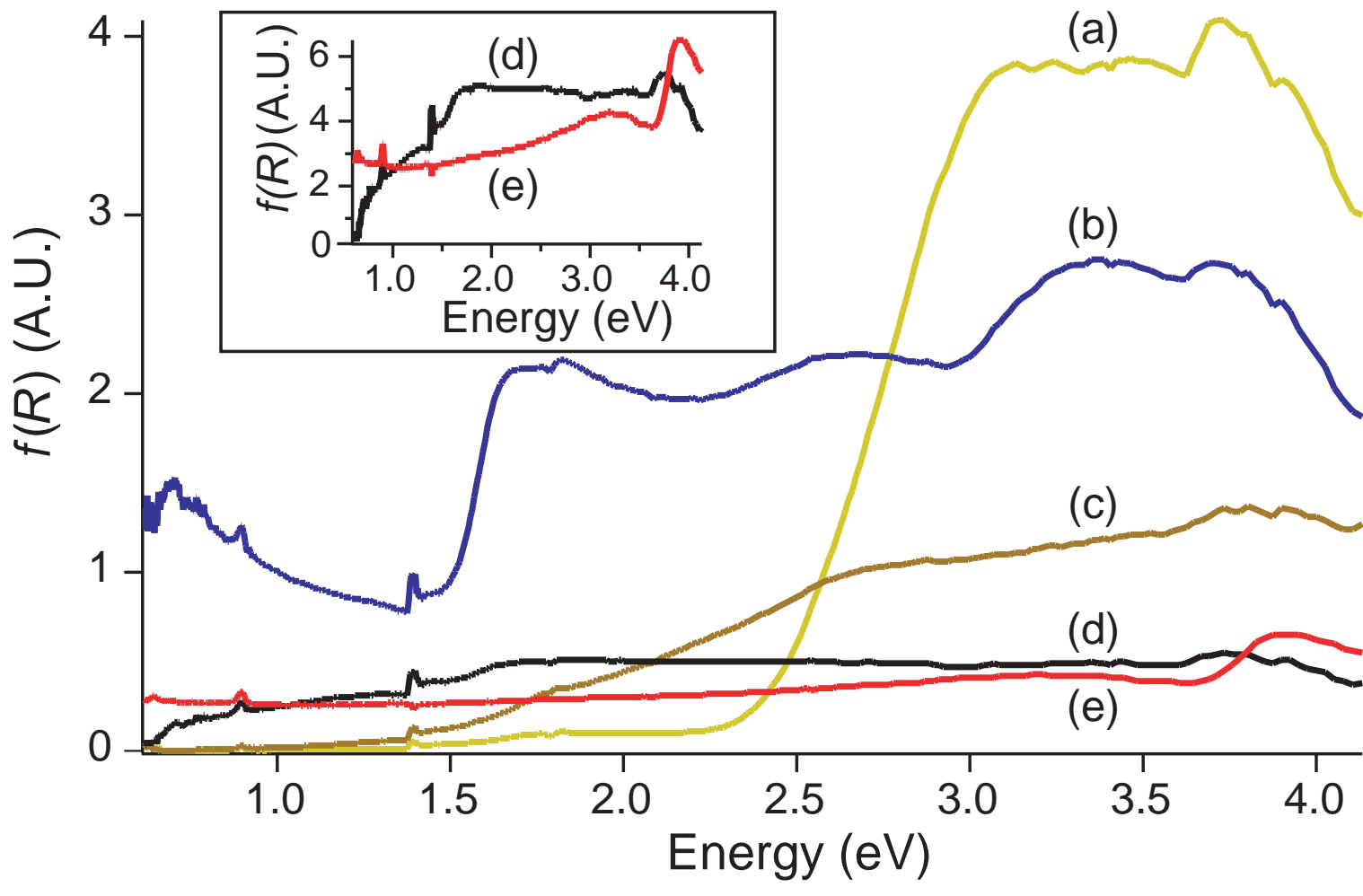

( Fig. 3 T. Naito et al. ) 